\title{
International regulations and environmental performance
}

\section{Barış K. Yörük \& Osnman Zaim}

To cite this article: Barıș K. Yörük \& Osnman Zaim (2008) International regulations and environmental performance, Applied Economics, 40:7, 807-822, DOI: $10.1080 / 00036840600749821$

To link to this article: http://dx.doi.org/10.1080/00036840600749821

\section{1.}

Submit your article to this journal

Щ Article views: 111

Q View related articles $\leftarrow$

4 Citing articles: 4 View citing articles ๘ 


\title{
International regulations and environmental performance
}

\author{
Barış K. Yörük $\mathrm{k}^{\mathrm{a}, *}$ and Osman Zaim ${ }^{\mathrm{b}}$ \\ ${ }^{a}$ Boston College Department of Economics, 140 Commonwealth Avenue, \\ Chestnut Hill, MA 02467-3806, USA \\ ${ }^{\mathrm{b}}$ Bilkent University Department of Economics, 06800 Bilkent, Ankara, \\ Turkey
}

This article employs the data envelopment analysis (DEA) approach to compute the environmental performance of all but two Organisation for Economic Co-operation and Development (OECD) countries. It is found that although the environmental performance of countries differs over time, Poland and Hungary are the two best performers for all periods while Italy, Japan, Austria and Switzerland are ranked among the worst. The effect of international regulations and some observed characteristics of countries on environmental performance are also investigated. International regulations are reported to have a positive effect on environmental performance.

\section{Introduction}

Increased awareness on environmental quality has prompted policy makers to adopt accurate measures and consider environmental impacts of their policy choices in the formulation of different economic policies. This not only prompts countries to measure, document and publish information about their environmental performance, but also brings proposals for a better environmental quality to international arena. OECD has a long-standing programme addressing environmental trends and their effects on economic policies. It undertakes outlooks of environmental trends, and works with its member countries to develop principles, guidelines and strategies for an effective management of the main environmental problems they face. Successful integration of environmental policies with sectoral and other economic policies is important to ensure that environmental policy goals are reached and the implications of other policy measures on the environment are addressed. Hence, as an initial step, accurate assessment of environmental trends and development of measures that will internalize negative externalities is essential for a successful environmental management in OECD.

In developing accurate environmental performance measures, an initial approach taken by international institutions such as the World Bank and OECD was based on either descriptive environmental indicators (e.g. measures of dissolved oxygen in water, suspended particular matter in air, soil salinization, etc.), or performance-based environmental indicators, which are measured against some physical threshold or normative policy goal (e.g. measures of compliance with international treaties or target levels of energy use per unit of output). However, these measures emphasize only environmental damage and losses without reconciling economic achievement with environmental goals. Owing to this fact, many recent studies propose alternative methodologies to investigate the impact of environmentally hazardous by-products using both micro and macro level data sets.

Recent literature on the measurement of environmental performance includes different methodologies

*Corresponding author. E-mail: yoruk@bc.edu 
that range from econometric estimation techniques to various optimization tools. Compared to other competing alternatives, nonparametric techniques and index number theory come up to be an attractive tool because of the advantages they possess. Obviously, the most useful and important advantage of this kind of approach is its convenience to allow one to make cross observation and over time comparisons easily. Moreover, in contrast to alternative approaches of its kind, this methodology allows for the construction of quantity indices without the need for price information on either inputs or outputs; therefore let one to proceed without constructing shadow prices. ${ }^{1}$

In his seminal paper, Farrell (1957), shows that how productive inefficiency and its components allocative and technical inefficiencies can be measured within a theoretically meaningful framework. Later, Färe et al. (1994) argue that how one can further decompose Farrell's measure of technical efficiency and extract information on the output loss due to deviations from optimal scale and congestion. This literature, ${ }^{2}$ known as 'production frontiers', is extensively covered in Shephard (1970), Färe et al. (1985) and Fried et al. (1993). In evaluating environmental performance and constructing the efficiency indices, two competing methodologies need to be mentioned. These are stochastic frontier estimation and data envelopment analysis (DEA). Both approaches are quite favourable in the literature. For example, Reinhard et al. (1999) employ a stochastic frontier approach to construct an environmental efficiency index on an application to Dutch dairy farms while Ball et al. (1994) adapt the DEA methodology to measure environmental performance in US agriculture. Alternatively, Tyteca (1997) develops an environmental performance indicator based on the decomposition of factor productivity into a pollution index with an application to data from US fossil fuel-fired electric utilities. Later, Reinhard (1997) employs both stochastic frontier estimation and DEA to show the pros and cons of two methods.

There are also alternative approaches according to the selection of the type of the efficiency measure in the studies that employ DEA framework. ${ }^{3}$ Färe et al. (1986, 1996) use radial measures of technical efficiency to compute a desirable output loss that stems from reduced disposability of undesirable outputs. In the latter work, they rely on the comparison of two input(output)-oriented radial technical efficiency scores; one accounts for the production of environmentally undesirable outputs and the other which completely ignores the production of pollutants with desirable outputs.

As opposed to the radial measure, the alternative efficiency measure is a hyperbolic measure of technical efficiency, which is suggested by Färe et al. (1989). Their measure of technical efficiency allows for simultaneous equiproportionate reduction in undesirable outputs (bads) with an expansion of desirable outputs (goods). The importance of this measure is to compute the opportunity cost of transforming the production process from one where all outputs are strongly disposable to the one, which is characterized by weak disposability of undesirable outputs. Later, hyperbolic measure of technical efficiency is employed in constructing environmental efficiency indices in the studies of Zaim and Taskin (1999), and Taskin and Zaim (2000). They employ this measure to construct an environmental efficiency index and measure the environmental performance of OECD countries.

In contrast to the studies cited, this article, using nonparametric techniques, employs an environmental performance index based on the well established methodology in a series of recent articles (Zaim et al., 2001; Färe et al., 2004; Zaim, 2004). Basically, this index is defined as the ratio of two indices, namely good (desirable) output quantity index and bad (undesirable) output quantity index. Similar to the well-known Malmquist index (Malmquist, 1953; Caves et al., 1982), both indices are developed using DEA framework and distance functions approach. However, in contrast to the Malmquist index, our indices employ sub-vector distance functions since they scale the good and bad outputs separately. The indices also satisfy various properties of index numbers due to Färe and Primont (1995) as well as the theoretical underpinnings established in Diewert (1981).

The organization of this article is as follows: Section II introduces the preliminaries for the theory of joint production of desirable and undesirable outputs and then proposes the methodology to construct the environmental performance index

\footnotetext{
${ }^{1}$ For the derivation of shadow prices for undesirable outputs, refer Färe et al. (1993).

${ }^{2}$ A comprehensive literature review can be found in Tyteca (1996).

${ }^{3}$ Data envelopment analysis approach is also employed under different contexts. Sengupta (2002), Womer (2003), and

Piot-Lepetit and Vermersch (1997) are the recent examples that appeared in this journal.
} 
employed in this study. Section III is reserved for the presentation of data and the results. Section IV investigates the country-specific factors that may affect the environmental performance and presents a discussion of the empirical results. Finally, Section V concludes.

\section{Joint Production of Desirable and Undesirable Outputs}

To describe the theoretical underpinnings of the model employed, let us denote desirable outputs by $y=\left(y_{1}, \ldots, y_{M}\right) \in R_{+}^{M}$ and undesirable outputs by $b=\left(b_{1}, \ldots, y_{I}\right) \in R_{+}^{I}$. Therefore, the output set $(y, b)$ is produced by the input set $x=\left(x_{1}, \ldots, x_{N}\right) \in R_{+}^{N}$. Then, technology can be described via its output set:

$$
T=\{(x, y, b): x \text { can produce }(y, b)\}
$$

In words, for each input vector $x=\left(x_{1}, \ldots, x_{N}\right) \in R_{+}^{N}$, the technology set includes all the combinations of good and bad outputs or the output set $(y, b)$, which can be produced by the vector of inputs. Technology set is also known as the output set $P(x)$ or can be represented by the input set $L(y, b)$ such that:

$$
(x, y, b) \in T \Leftrightarrow(y, b) \in P(x) \Leftrightarrow x \in L(y, b)
$$

The weak disposability assumption ${ }^{4}$ of output set $(y, b)$ can be modelled as:

$$
(y, b) \in P(x) \text { and } 0 \leq \theta \leq 1 \text { imply }(\theta y, \theta b) \in P(x)
$$

In words, this assumption implies that given a fixed level of inputs, a reduction in bads is feasible only when the goods are also simultaneously reduced. On the other hand, good outputs may be reduced without the reduction of the bad outputs. Free disposability of good outputs is formally:

$$
(y, b) \in P(x) \text { and } y^{\prime} \leq y \text { imply }\left(y^{\prime}, b\right) \in P(x)
$$

Equations 3 and 4 together model the asymmetry between the good and bad outputs where goods are freely disposable while the bads are not. On the other hand, the assumption of null-jointness implies that no desirable outputs can be produced without producing any undesirable outputs. This idea of joint production of good and bad outputs can be modelled as:

$$
\text { if }(y, b) \in P(x) \text { and } b=0 \text { then } y=0
$$

In addition to the assumptions on the joint production of good and bad outputs, we may also impose some restrictions over the output set $P(x)$. To model the idea that zero inputs yield zero outputs we have:

$$
P(0)=\{0,0\}
$$

Moreover, given finite inputs, only finite outputs can be produced. Formally:

$$
P(x) \text { is compact for each } x \in R_{+}^{N}
$$

The final assumption on output set $P(x)$ is:

$$
P(x) \supseteq P\left(x^{\prime}\right), x \geq x^{\prime}
$$

This assumption imposes free disposability of inputs, which essentially implies that if inputs are increased then outputs do not decrease.

Following Färe et al. (1994), we may formulate an activity analysis or DEA. We assume that there are $K$ observations on inputs and outputs, where $k$ indexes each individual observation such that $\left\{\left(x^{k}, y^{k}, b^{k}\right): k=1, \ldots, K\right\}$. Using this data, we construct an output set that holds for every period and satisfies our previous assumptions. Formally, we have:

$$
\begin{aligned}
& P(x)=\left\{(y, b): \quad \sum_{k=1}^{K} z_{k} y_{k m} \geq y_{m}, \quad m=1, \ldots, M,\right. \\
& \sum_{k=1}^{K} z_{k} b_{k i}=b_{i}, \quad i=1, \ldots, I, \\
& \sum_{k=1}^{K} z_{k} x_{k n} \leq x_{n}, \quad n=1, \ldots, N, \\
& \left.z_{k} \geq 0, \quad k=1, \ldots, K\right\}
\end{aligned}
$$

where the non-negative $z_{k}$ are the intensity variables (weights) assigned to each observation when constructing the production set. The inequality constraint on the good output $y=\left(y_{1}, \ldots, y_{M}\right) \in$ $R_{+}^{M}$ in (9) states the assumption of free disposability, which implies that desirable outputs can be disposed off without the use of any inputs. If we consider the joint production of undesirable outputs $b=\left(b_{1}, \ldots, y_{I}\right) \in R_{+}^{I}$ with desirable outputs, we should impose the weak disposability condition that satisfies the assumption introduced in (3) by choosing an equality sign for the relevant constraint. To satisfy the null-jointness introduced before, we restrict the conditions:

$$
\sum_{k=1}^{K} b_{k i}>0, \quad i=1, \ldots, I,
$$

\footnotetext{
${ }^{4}$ For a detailed exposition on the assumptions of production frontiers, one can refer to Chung et al. (1997) or Shephard and Färe (1974).
} 
and

$$
\sum_{i=1}^{I} b_{k i}>0, \quad i=1, \ldots, K,
$$

The inequality (10) states that each undesirable or bad output is produced by some individual sample $k$. On the other hand, (11) implies every $k$ produces at least one bad output. We may further illustrate nulljointness by assuming that each $b_{i}=0$, where $i=1, \ldots, I$. Then each intensity variable $z_{k}$ in (9) will be zero, implying that all the desirable good outputs $y_{m}$ must be zero. Therefore, these two restrictions can be used to determine whether a particular data set satisfies null-jointness of desirable and undesirable outputs. Imposing this assumption, our application will not include the data that violate the nulljointness.

Further, the non-negativity of intensity variables in (9) implies that the production technology exhibits constant returns to scale. That is

$$
P(\lambda X)=\lambda P(x), \lambda>0
$$

\section{Environmental performance index}

Following Zaim et al. (2001), the environmental performance index employed in this article is the ratio of two indices, namely, good output quantity index and bad output quantity index. This index employs sub-vector distance functions since it scales the good and bad outputs separately. It also satisfies the desirable properties such as closedness and convexity due to Färe and Primont (1995). We formally define a sub-vector distance function for good outputs as:

$$
D_{y}(x, y, b)=\inf \{\theta:(x, y / \theta, b) \in T\}
$$

which holds the inputs and bad outputs fixed and expands the good outputs as much as it is feasible. Note that it is also homogeneous of degree +1 in $y$. Keeping this notation in mind, let $x^{0}$ and $b^{0}$ be given inputs and bad outputs, then taking the ratio of two distance functions, good output quantity index compares two output vectors $y^{k}$ and $y^{l}$. Hence, quantity index for the goods is:

$$
Q_{y}\left(x^{0}, b^{0}, y^{k}, y^{l}\right)=\frac{D_{y}\left(x^{0}, y^{k}, b^{0}\right)}{D_{y}\left(x^{0}, y^{l}, b^{0}\right)}
$$

On the other hand, the quantity index of bad outputs is constructed using an input distance function approach. The input-based distance function for bad outputs is:

$$
D_{b}(x, y, b)=\sup \{\lambda:(x, y, b / \lambda) \in T\}
$$

which is homogeneous of degree +1 in bad outputs and is defined by finding the maximal contraction in undesirable outputs. Given $\left(x^{0}, y^{0}\right)$, the quantity index of bad outputs can be computed as the ratio of two distance functions:

$$
Q_{b}\left(x^{0}, y^{0}, b^{k}, b^{l}\right)=\frac{D_{b}\left(x^{0}, y^{0}, b^{k}\right)}{D_{b}\left(x^{0}, y^{0}, b^{l}\right)}
$$

Finally, the environmental performance index defined is the ratio of Equations 16 and 14, i.e.:

$$
P^{k . l}\left(x^{0}, y^{0}, b^{0}, y^{k}, y^{l}, b^{k}, b^{l}\right)=\frac{Q_{b}\left(x^{0}, y^{0}, b^{k}, b^{l}\right)}{Q_{y}\left(x^{0}, b^{0}, y^{k}, y^{l}\right)}
$$

\section{Data and Discussion of Results}

The resource constraint (inputs) in constructing the environmental performance index is represented by net fixed standardized capital stock and labour (number of employed workers), whereas the outputs are GDP (PPP adjusted with 1996 prices), industrial carbon dioxide $\left(\mathrm{CO}_{2}\right)$, nitrogen oxide $\left(\mathrm{NO}_{x}\right)$ and organic water pollutant emissions. The data on capital stock, labour and GDP are compiled from a recent data set (Marquetti, 2002). World Development Indicators (World Bank, 2002) is the source for $\mathrm{CO}_{2}$ and organic water pollutant emissions data, whereas the data for $\mathrm{NO}_{x}$ emissions ${ }^{5}$ are compiled from the World Marketing Database (Euromonitor, 2002). Carbon dioxide and nitrogen oxide emissions from industrial processes are those arising from the burning of fossil fuels. They include contributions to $\mathrm{CO}_{2}$ and $\mathrm{NO}_{x}$ produced during consumption of solid, liquid, gas fuels and gas flaring. Emissions of organic water pollutants are measured by biochemical oxygen demand, which refers to the amount of oxygen that bacteria in water will consume in breaking down waste. This is a standard water treatment test for the presence of organic pollutants. The annual data set includes 28 OECD countries. Slovak Republic and Czech Republic are excluded due to the unavailability of the data for these countries. The time period considered is 16 years, from 1983 to 1998.

\footnotetext{
${ }^{5}$ Carbon dioxide emissions are measured in '000 kt. Nitrogen oxide emissions are measured in '000 kt. Organic water pollutant emissions are measured in ' $000 \mathrm{~kg}$ per day. Interpolation techniques are used to fill the missing values.
} 
In constructing the environmental performance indices, previous studies ${ }^{6}$ assign a reference country so as to construct a benchmark technology and then compute the distance of other observations from the reference observation. This technique assesses the performance of the countries relative not to average but to a particular country. Moreover, the reference country takes the value of unity for all time periods for the index computed, which means to exclude the performance of the reference country. To overcome this shortcoming, we start our analysis by creating a hypothetical country. The data for the hypothetical country is simply calculated by taking the average of each variable for all sample OECD countries. Assigning the hypothetical country as our reference, we are able to compute the environmental performance of OECD countries relative to the average performance.

Although our data set includes three undesirable outputs, we employed the pollutant data as pairs and computed environmental performance indices that incorporate $\mathrm{NO}_{X}$ and $\mathrm{CO}_{2}, \mathrm{NO}_{X}$ and organic water pollutant and $\mathrm{CO}_{2}$ and organic water pollutant emissions, respectively. The main reason for employing the pollutant data as pairs is our effort to reduce the number of infeasible solutions. As the number of time periods and variables in the linear programming problems increase, one should also expect a simultaneous increase in the number of infeasible solutions. ${ }^{7}$ To overcome this issue as much as possible, following Färe et al. (2001), we assumed that each year's technology is determined by observations on inputs and outputs of current and past two periods. Moreover, the data being evaluated are also chosen to be 3-year moving averages in order to smooth the data and reduce the number of infeasible solutions.

In order to compute the environmental performance index, we need to solve two linear programming problems by employing DEA methodology. Assuming that $j=0$ refers to the associated quantities of hypothetical country and letting $k=1, \ldots, K$ to index the countries in our sample, for each country $k^{\prime}=1, \ldots, K$, we may compute for each sub-period (year)

$$
\begin{array}{ll}
\left(D_{y}\left(x^{0}, y^{k^{\prime}}, b^{0}\right)\right)^{-1}=\max \theta & \\
\text { s.t. } & \\
\sum_{k=1}^{K} z_{k} y_{m}^{k} \geq \theta y_{m}^{k^{\prime}} & m=1, \ldots, M \\
\sum_{k=1}^{K} z_{k} b_{j}^{k}=b_{j}^{0} & j=1, \ldots, J \\
\sum_{k=1}^{K} z_{k} x_{n}^{k} \leq x_{n}^{0} & n=1, \ldots, N \\
z_{k} \geq 0 & k=1, \ldots, K
\end{array}
$$

which constitutes the numerator for $Q_{y}\left(x^{0}, b^{0}, y^{k}, y^{l}\right)$. The denominator is computed by replacing $y^{k^{\prime}}$ on the right hand side of the good output constraint with the observed output for the hypothetical country $\left(y^{0}\right)$. This problem constructs the best practice frontier for each sub-period and computes the scaling factor on good outputs required for each observation to attain best practice.

On the other hand, the quantity index of bads can be computed by solving the following problem for each country $k^{\prime}=1, \ldots, K$ :

$$
\begin{array}{ll}
\left(D_{b}\left(x^{0}, y^{0}, b^{k \prime}\right)\right)^{-1}=\min \lambda & \\
\text { s.t. } & \\
\sum_{k=1}^{K} z_{k} y_{m}^{k} \geq y_{m}^{0} \quad m=1, \ldots, M \\
\sum_{k=1}^{K} z_{k} b_{j}^{k}=\lambda b_{j}^{k^{\prime}} \quad j=1, \ldots, J \\
\sum_{k=1}^{K} z_{k} x_{n}^{k} \leq x_{n}^{0} \quad n=1, \ldots, N \\
z_{k} \geq 0 & k=1, \ldots, K
\end{array}
$$

This problem constitutes the numerator for $Q_{b}\left(x^{0}, b^{0}, y^{k}, y^{l}\right)$. The denominator is computed by replacing $b^{k^{\prime}}$ on the right hand side of the bad output constraint with the observed bad outputs for the hypothetical country $\left(b^{0}\right)$. Similar to the quantity index of goods, this problem constructs the best practice frontier and computes the scaling factor on bad outputs required for each observation to attain the best practice.

In Table $1,{ }^{8}$ we report the environmental performance index that incorporates both $\mathrm{NO}_{X}$ and

\footnotetext{
${ }^{6}$ See, for example, Färe et al. (2004) and Zaim et al. (2001). Färe et al. (2004) use a lattice approach to create a reference country. However, our approach is let us to evaluate the individual performances of our countries compared to that of an 'average country'. We thank an anonymous referee for pointing this out.

${ }^{7}$ For further discussion on infeasible solutions on linear programming problems, see Färe et al. (2001).

${ }^{8}$ Country codes are as follows: AUS: Australia, AUT: Austria, BEL: Belgium, CAN: Canada, DNK: Denmark, FIN: Finland, FRA: France, GER: Germany, GRC: Greece, HUN: Hungary, ISL: Iceland, IRL: Ireland, ITA: Italy, JPN: Japan, KOR: Korea, LUX: Luxembourg, MEX: Mexico, NLD: Netherlands, NZL: New Zealand, NOR: Norway, POL: Poland, PRT: Portugal, ESP: Spain, SWE: Sweden, CHE: Switzerland, TUR: Turkey, GBR: Great Britain, USA: United States.
} 
|

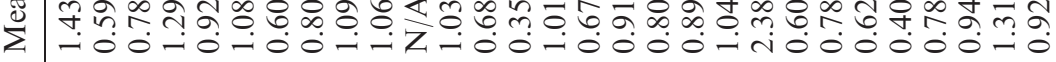

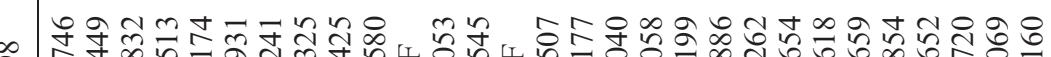

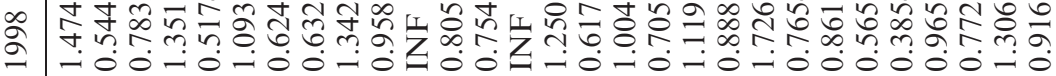

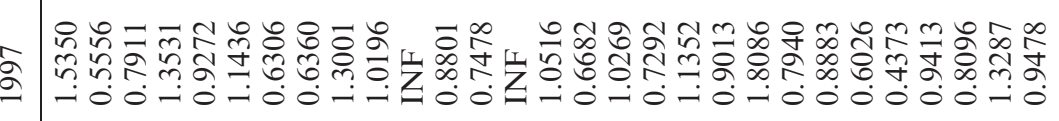

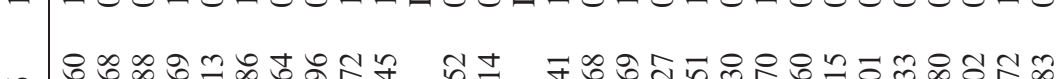

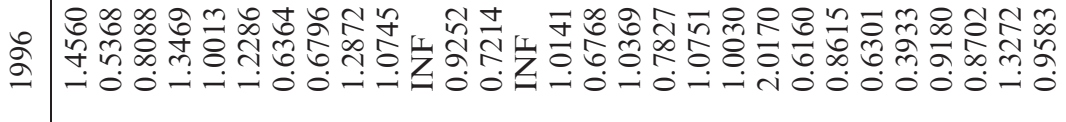

そ

Ә

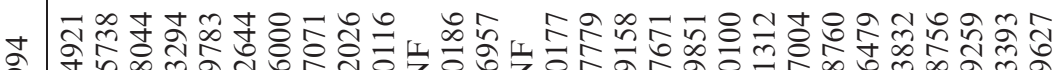

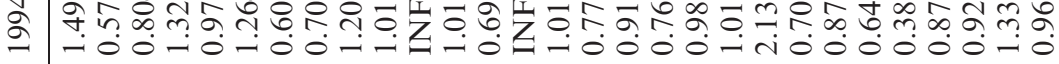

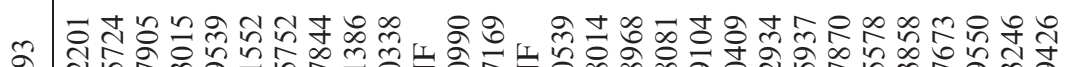

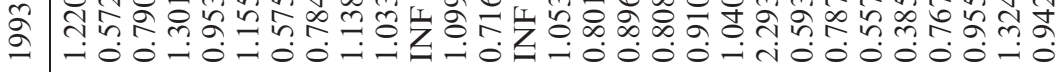

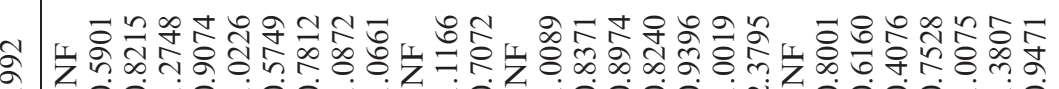

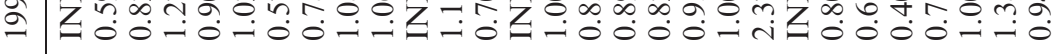

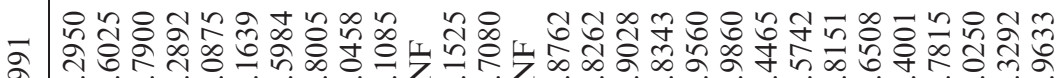

$\checkmark$ N

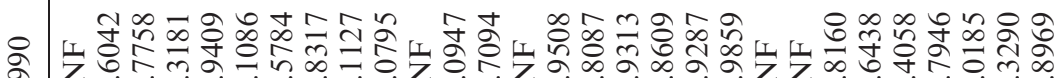

a

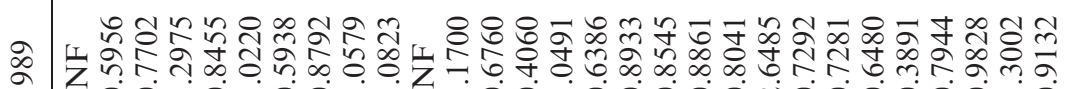

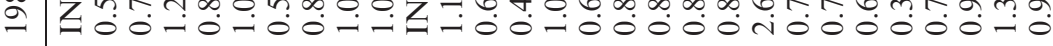

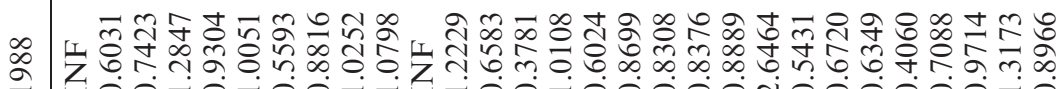

-

ڤ

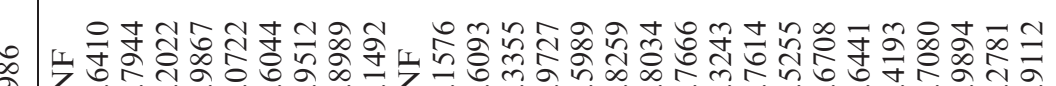

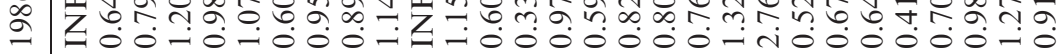

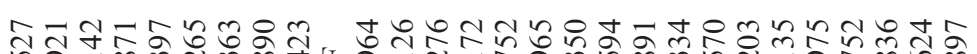

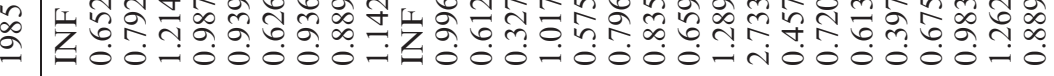

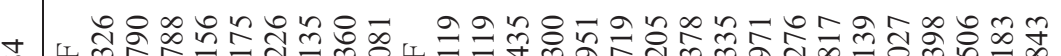

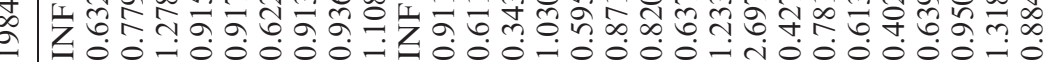

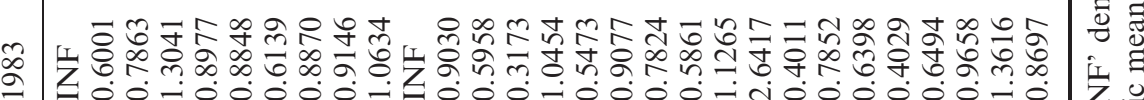


$\mathrm{CO}_{2}$ emissions. It should be indicated that, figures $>1(<1)$ represent a better (inferior) performance with respect to the hypothetical country. Note that hypothetical country takes the value of unity for all years and all indices and is not reported in the tables. Taking a quick glance at Table 1 which reveals that Poland, Australia, Canada and USA are among the best performers and have kept their position over the time period considered. On the other hand, Switzerland, Japan, Austria and France ranked among the worst for the period 1983 to 1998. It is observed that on average, environmental performance of the sample countries has decreased approximately $7 \%$ to $13 \%$ for the time span considered. It should also be stated that environmental performance index could not be computed for Iceland because of the infeasible solutions. ${ }^{9}$

Table 2 presents the environmental performance index that incorporates $\mathrm{NO}_{X}$ and organic water pollutant emissions. We observe that over the time period, Poland, Iceland, Portugal and Hungary are the best performers. One of the best performers in Table 1, namely Australia is among the worst performers in Table 2, along with Italy, Mexico and Switzerland. According to Table 2, OECD countries present a significant performance in environmental management $(8-11 \%$ per annum on average). Finally, in contrast to Table 1, environmental performance index could not be computed for Japan.

In Table 3, we report the environmental performance index that incorporates $\mathrm{CO}_{2}$ and organic water pollutant emissions. One can clearly recognize that as in Table 1, environmental performance index for Iceland could not be computed. Surprisingly, although we employed different pollutant emission pairs, Poland is the best performer for all years like in Tables 1 and 2. One can also see that Hungary, Luxembourg and Korea are among the best achievers. The worst performers in Table 3 are Mexico, Switzerland and Italy. Overall, this index reveals an approximately $2 \%$ decrease in the environmental performance for the period 1992 to 1998 while for the rest of the years it reveals an approximately $1 \%$ increase on average.

Taking relatively low-income countries into picture, the results revealed by our environmental performance index that incorporates different pollutant pairs and the ones reported by the traditional measures which attempt to assess the environmental performance by simply computing emissions per GDP, are generally in line. For example, the most recent OECD report (2004) on selected environmental indicators ranks Poland and Hungary among the best as our environmental performance indices have suggested. However, when it comes to relatively highincome countries, this fact does not hold. In contrast to our measure, the OECD report (2004) ranks USA and Australia among the worst. This result was expected since traditional measures ignore the fact that aggregate environmental degradation is a consequence of production process and hence, weak disposability assumption ${ }^{10}$ introduced in (3) should be imposed to construct reliable measures.

To present a clear exposition, the quantity indices for undesirable outputs are also reported in appendix tables. Since the environmental performance index is the ratio of bad quantity index over good quantity index, the exact numbers can easily be computed for respective quantity indices for desirable outputs. These tables are useful as they highlight the undesirable output production of respective country. For example, when comparing Table 1 with Table A1, we observe that although USA has incredibly high $\mathrm{CO}_{2}$ and $\mathrm{NO}_{x}$ emissions, it is still making an environmentally efficient performance because of its superior performance in the production of desirable goods.

\section{Empirical Analysis}

In our empirical analysis, we investigate the countryspecific variables that may affect environmental performance. Our explanatory variables are GDP per capita (GDPC), share of manufacturing in GDP (MANSHARE), population density (POPDEN) and regulation. Regulation is a dummy variable which takes the value of unity for the year that the sample country has ratified the United Nations Framework Convention on Climate Change (1992) and thereafter. ${ }^{11}$ It should be noted that starting from 1992, all

\footnotetext{
${ }^{9}$ Infeasible solutions are denoted in the tables by INF.

${ }^{10}$ Especially in regulated environments, where production units are required to clean up the undesirable outputs, one has to treat undesirable and desirable outputs asymmetrically in terms of their disposability characteristics. Even in the absence of regulations, the same claim may hold because of the increased environmental consciousness in the society.

${ }^{11}$ UNFCCC is declared to reduce global emissions. The 'precautionary approach' the article 3 of UNFCCC calls for a production plan that is least detrimental to environmental quality. That is among many input, output and pollution emission combinations, the production plan that maximizes the desirable outputs while simultaneously minimizing undesirable outputs is more favourable. The building blocks of our environmental performance index are in accordance with this statement.
} 
|

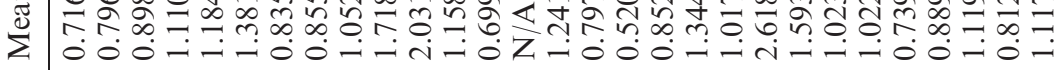

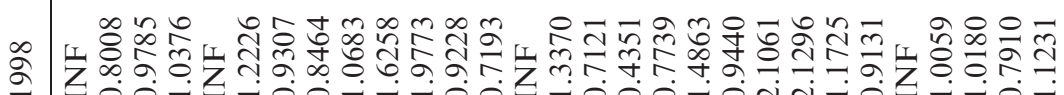

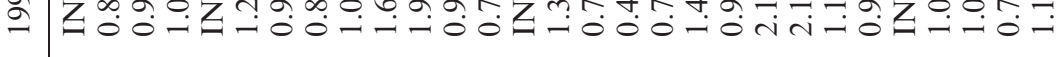

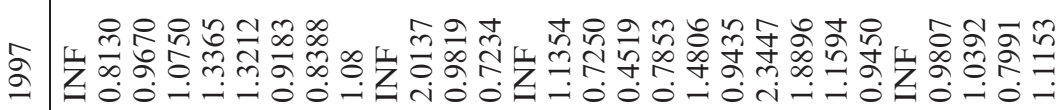

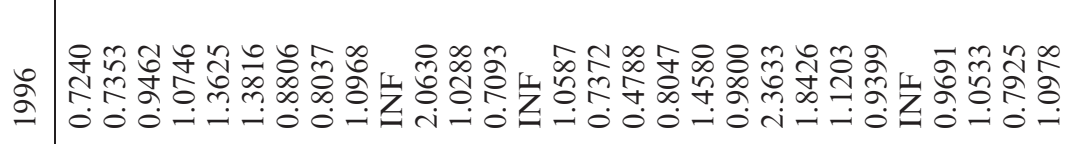

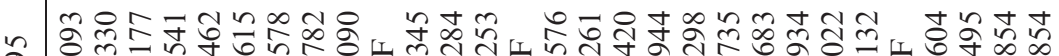
à

4

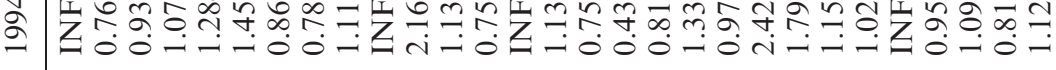

๙

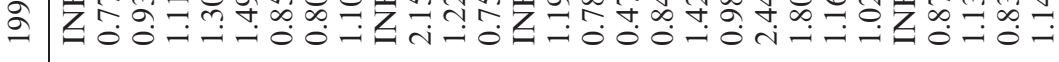

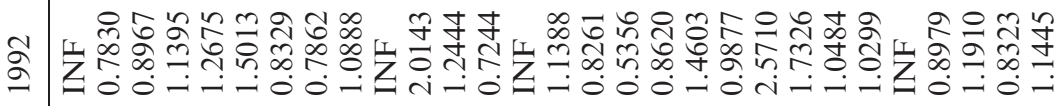

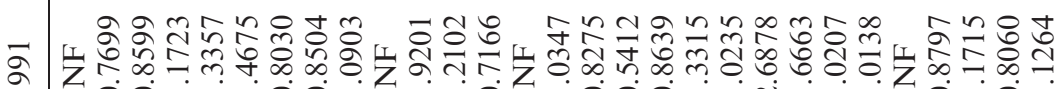

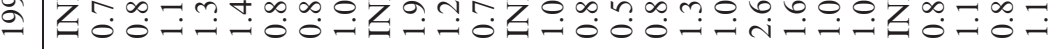

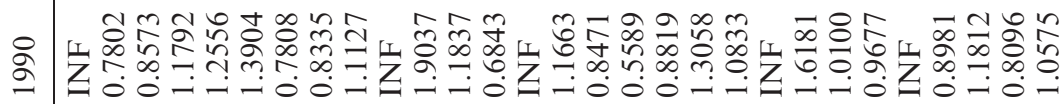

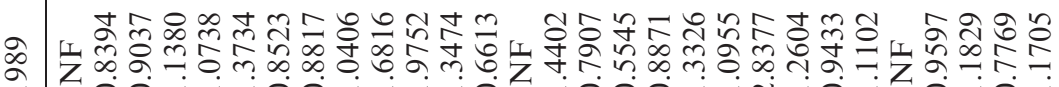

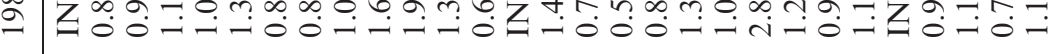

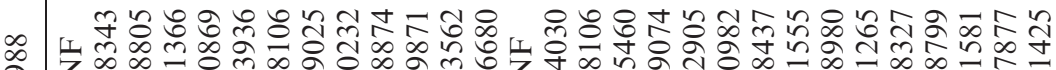

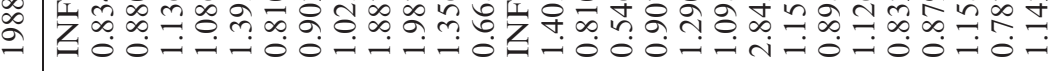

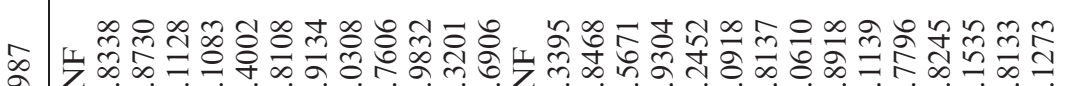

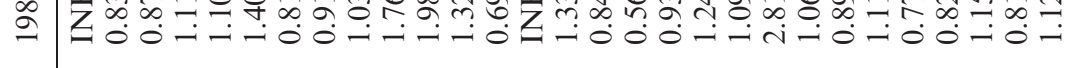

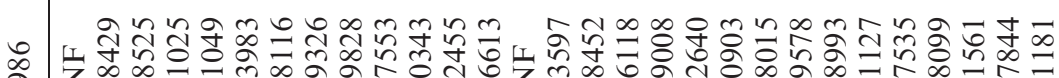

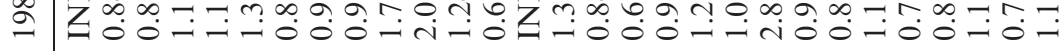

œ

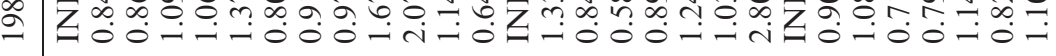

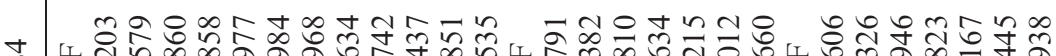

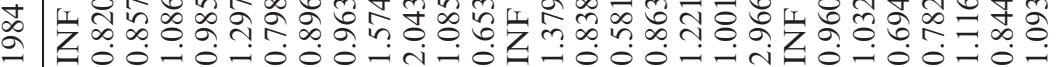

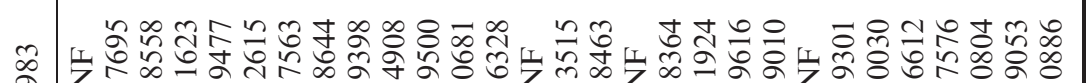
$\leadsto$ Z

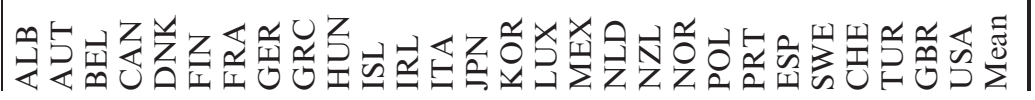


政 之

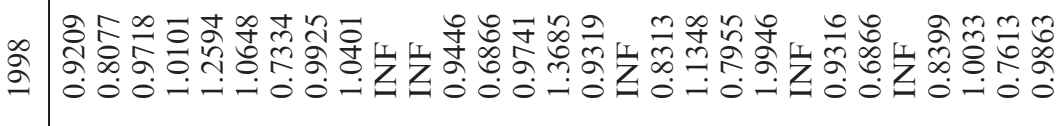

ลิ ब

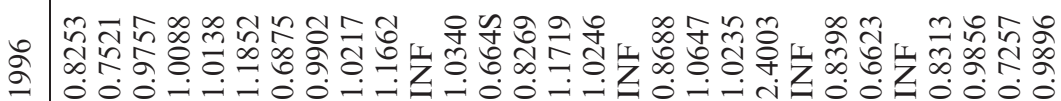

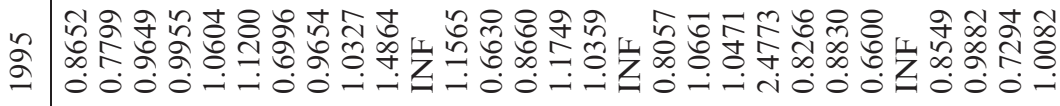

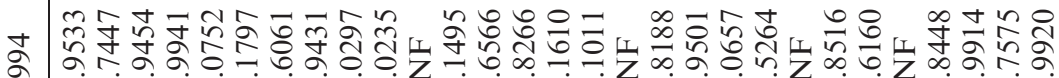
a

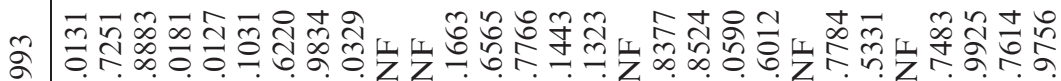

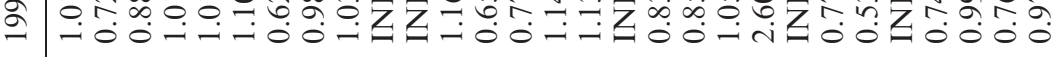

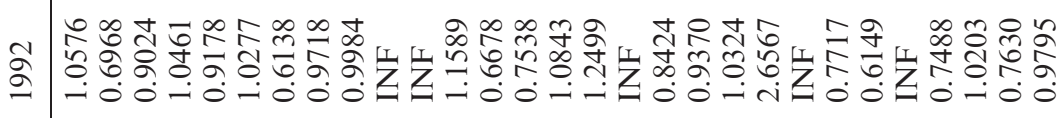

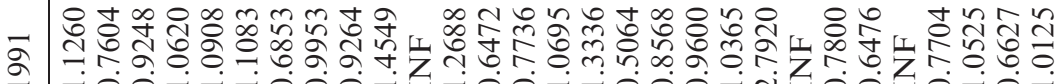

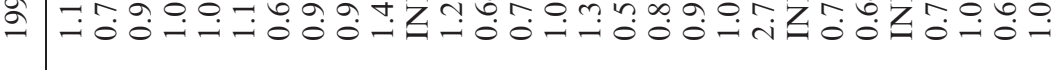

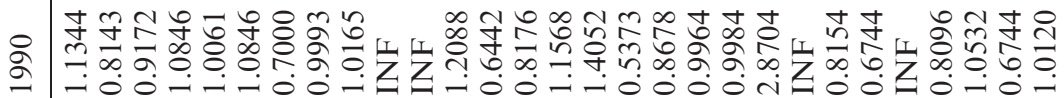

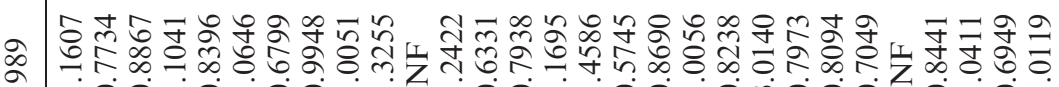
$=$ - 0 o

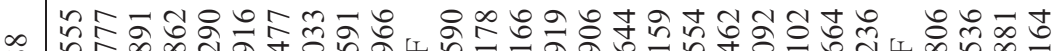

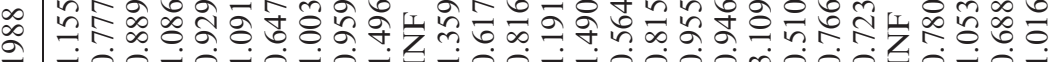

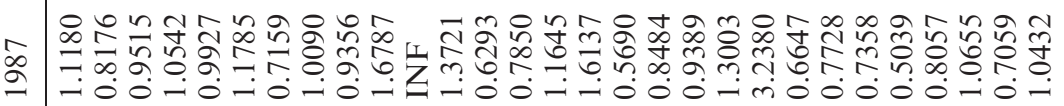
॰

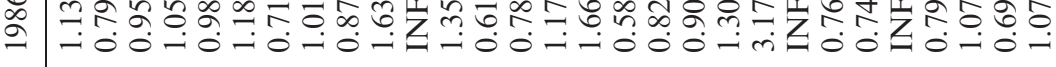

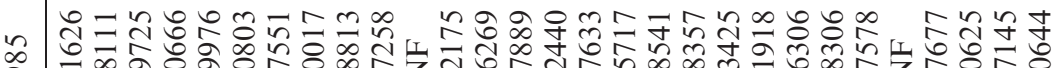

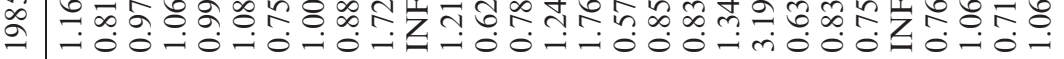

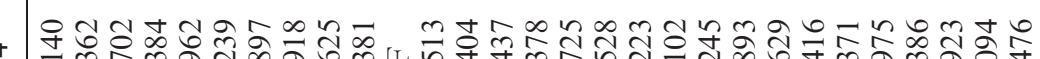

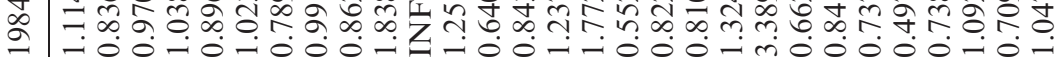

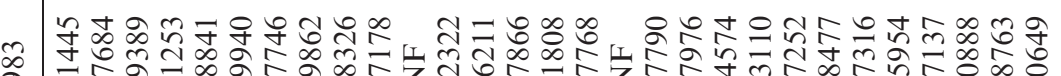

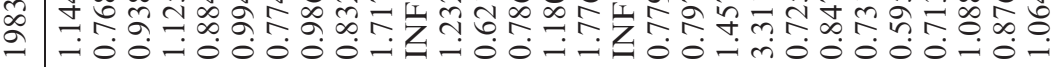

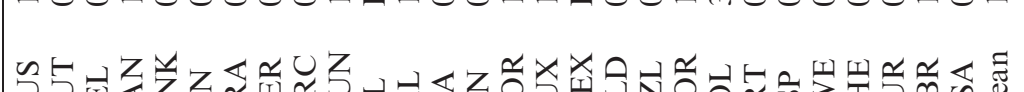


the countries in our sample have ratified this convention until 1996 with an exception of Turkey which has ratified the convention in 2002. The square of GDPC and MANSHARE are also included in order to depict any quadratic relationship between environmental performance and these variables. The source for the explanatory variables except the regulation dummy is World Development Indicators (World Bank, 2002).

Under two alternative specifications (fixed effects and random effects models), Table 4 provides parameter estimates of the relevant regressions for all environmental performance indices computed. The choice between random effects and fixed effects model can be made using the Hausman test which has an asymptotic $\chi_{k-1}^{2}$ distribution. The parameter estimates, which are all significant at conventional levels, suggest a quadratic relationship between environmental performance and the two independent variables MANSHARE and GDPC except for the case when our dependent variable is the environmental performance index that incorporates $\mathrm{NO}_{X}$ and organic water pollutant emissions. The quadratic relationship between environmental performance and MANSHARE is inverse $U$ type with a turning point of approximately 0.20 . This suggests that, if the share of manufacturing in GDP increases beyond 20\%, there would be a downward trend in environmental performance. On the other hand, positive and statistically significant coefficient of the regulation variable implies an upward pressure on environmental performance of the OECD countries that ratified the United Nations Convention on Climate Change to reduce air pollution emissions. ${ }^{12}$ Finally, negative and highly significant coefficient of POPDEN implies that densely populated OECD countries are more likely to exhibit poor environmental performance in reducing their $\mathrm{NO}_{X}$ and water pollutant emissions.

At a more fundamental level, one would consider how the findings of this article may relate to environmental Kuznets curve hypothesis. In a short note, Yörük and Zaim (2006) use the results of this article to establish an environmental Kuznets curve relationship between environmental performance and income. They found that Kuznets curve achieves its maximum at relatively high per capita income levels (\$26973 and \$33677 under different specifications) suggesting that even most of the industrialized countries are not necessarily adhering to environmental standards and their environmental conditions are deteriorating with economic growth. However, once the stated income levels are reached, concerns about environment become increasingly pronounced and necessary regulations take place to reduce relevant emissions to desirable levels.

\section{Conclusion}

This article is aimed to measure the environmental performance of all but two OECD countries. Using nonparametric techniques, we proposed an environmental performance index by adopting a wellestablished methodology in a series of recent papers (Zaim et al., 2001; Färe et al., 2004; Zaim, 2004). This index relies on the computation of the distance functions within a DEA framework and allows one to evaluate how much good output is produced per bad output.

We computed three different environmental performance indices that employ different pollutant emission pairs. Although the ranking and environmental performances of countries differ over time and according to the pollutants considered, it is found that Poland and Hungary are the best performers for all indices, while Italy, Japan, Austria and Switzerland are among the worst. It should also be noted that environmental performance index that incorporates $\mathrm{NO}_{X}$ and organic water pollutant emissions reveals significantly higher environmental performance figures than other indices. The results showed that some industrialized and well-developed countries are ranked among the worst in terms of their environmental efficiency. We also noted that when we consider relatively low-income countries, the results revealed by our environmental performance index that incorporates different pollutant pairs and the ones reported by the traditional measures which attempt to assess the environmental performance by computing emissions per GDP are generally in line. However, when it comes to relatively high-income countries, this result does not hold.

We also investigated a set of country-specific variables that may possibly affect environmental performance. We found that as the share of manufacturing in GDP increases beyond $20 \%$, there is a downward trend in environmental performance. On the other hand, positive and statistically significant coefficient of the regulation variable implies an

\footnotetext{
${ }^{12}$ Yörük and Zaim (2005) and Yörük (2006) show the positive effect of UNFCCC on productivity growth measures that incorporate negative externalities. However, they do not address the effect of UNFCCC on environmental performance.
} 


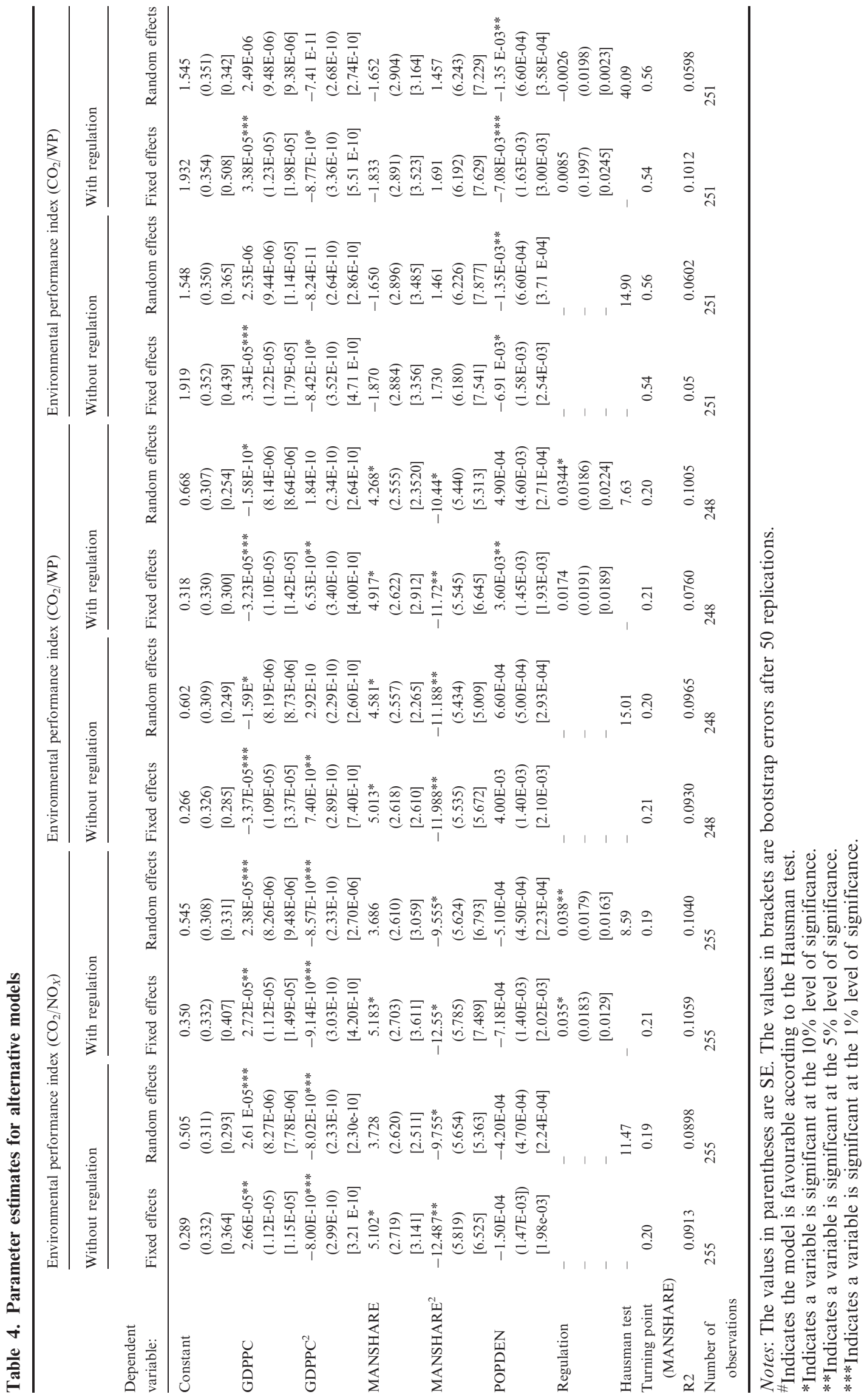


upward pressure on environmental performance of the OECD countries, which ratified the United Nations convention on climate change to reduce the air pollution emissions.

\section{Acknowledgements}

We would like to express our gratitude to Syed Mahmud, Süheyla Özyıldırım, Frank Gollop and Asel Aliyosova. All errors remain ours.

\section{References}

Ball, V. E., Knox Lovell, C. A., Nehring, R. F. and Somwaru, A. (1994) Incorporating undesirable outputs into models of production: an application to the US agriculture, Cahiers d'Economie et Sociologie Rurales, 31, 60-74.

Caves, D. W., Christensen, L. R. and Diewert, W. E. (1994) The economic theory of index numbers and the measurement of input, output and productivity, Econometrica, 50, 1393-414.

Chung, Yi. H., Färe, R. and Grosskopf, S. (1997) Productivity and undesirable outputs: a directional distance function approach, Journal of Environmental Management, 51, 229-40.

Diewert, W. E. (1981) The economic theory of index numbers: a survey, in Essays in the Theory and Measurement of Consumer Behaviour in Honour of Sir Richard Stone (Ed.) A. Deaton, Cambridge University Press, Cambridge, pp. 163-208.

Euromonitor (2002) World Marketing Database, Dataset.

Färe, R. and Knox Lovell, C. A. (1985) The Measurement of Efficiency of Production, Kluwer-Nijhoff, Boston.

Färe, R., Knox Lovell, C. A. and Pasurka, C. A. (1989) Multilateral productivity comparisons when some outputs are undesirable, Review of Economics and Statistics, 71, 90-8.

Färe, R, et al. (1993) Derivation of shadow prices for undesirable outputs: a distance function approach, Review of Economics and Statistics, 75, 374-80.

Färe, R. and Primont, D. (1995) Multi-Output Production and Duality: Theory and Applications, Kluwer Academic Publishers, Boston.

Färe, R., Grosskopf, S. and Knox Lovell, C. A. (1994) Production Frontiers, Cambridge University Press, Cambridge.

Färe, R., Grosskopf, S. and Pasurka, C. A. (1986) Effects on relative efficiency in electric power generation due to environmental controls, Resources and Energy, 8, $167-84$.

Färe, R., Grosskopf, S. and Pasurka, C. A. (2001) Accounting for air pollution emissions in measures of state manufacturing productivity growth, Journal of Regional Science, 41, 381-409.

Färe, R., Grosskopf, S. and Tyteca, D. (1996) An activity analysis model of the environmental performance of firm: application to fossil fuel electric utilities, Ecological Economics, 18, 161-75.
Färe, R., Grosskopf, S. and Sancho, H. (2004) Environmental performance: an index number approach, Resource and Energy Economics, 26, 343-52.

Farrell, M. J. (1957) The measurement of productive efficiency, Journal of Royal Statistics Society Series A, 120, 253-81.

Fisher, I. (1922) The Making of Index Numbers, HoughtonMifflin, Boston.

Fried, H. O., Knox Lovell, C. A. and Schmidt, S. S. (1993) The Measurement of Productive Efficiency: Techniques and Applications, Oxford University Press, Oxford.

Malmquist, S. (1953) Index numbers and indifference surfaces, Trabajos de Estadistica, 4, 209-42.

Marquetti, A. (2002) Extended Penn World Tables 2.0. Data Set, Available at http://homepage.newschool.edu/ $\sim$ foleyd/epwt/ (accessed 1 June 2006).

OECD Key Environmental Indicators (2004) OECD Environmental Directorate, Paris, France.

Piot-Lepetit, I., Vermersch, D. and Weaver, R. D. (1997) Agriculture's environmental externalities: DEA evidence for French agriculture, Applied Economics, 29, 331-38.

Reinhard, S., Knox Lovell, C. A. and Thijssen, G. J. (2000) Environmental Efficiency with Multiple Environmentally Detrimental Variables: estimated with SFA and DEA, European Journal of Operational Research, 121, 287-303.

Reinhard, S., Knox Lovell, C. A. and Thijssen, G. J. (1999) Econometric estimation of technical and environmental efficiency: an application to Dutch dairy farms, American Journal of Agricultural Economics, 81, 44-60.

Sengupta, J. K. (2002) Economics of efficiency measurement by the DEA approach, Applied Economics, 24, 1133-39.

Shephard, R. W. (1970) Theory of Cost and Production Frontiers, Princeton University Press, Princeton, NJ.

Shephard, R. W. (1974) Laws of diminishing returns, Zeitschrift für Nationalökonomie, 34, 69-90.

Taskin, F. and Zaim, O. (2000) Searching for a Kuznets curve in environmental efficiency using Kernel estimation, Economics Letters, 68, 217-23.

Tyteca, D. (1996) On the measurement of environmental performance of firms: a literature review and a productive efficiency perspective, Journal of Environmental Management, 46, 281-308.

Tyteca, D. (1997) Linear programming models for the measurement of environmental performance of firmsconcepts and empirical results, Journal of Productivity Analysis, 8, 183-97.

World Bank (2002) World Development Indicators, Data Set, World Bank, Washington, D.C.

Womer, N. K., et al. (2003) Measuring efficiency with a linear economic model, Applied Economics, 35, 1459-67.

Yörük, B. K. (2007) Negative externalities, productivity growth, and the catching-up hypothesis, Applied Economics Letters, 14, 429-34.

Yörük, B. K. and Zaim, O. (2005) Productivity growth in OECD countries: a comparison with Malmquist indices, Journal of Comparative Economics, 33, 401-20.

Yörük, B. K. and Zaim, O. (2006) The Kuznets curve and the effect of international regulations on environmental efficiency, Economics Bulletin, 17, 1-7. 
Zaim, O. (2004) Measuring environmental performance of state manufacturing through changes in pollution intensities: a DEA framework, Ecological Economics, 48, 37-47.

Zaim, O. and Taskin, F. (1999) A Kuznets curve in environmental efficiency: an application on OECD countries, Environmental and Resource Economics, 17, 21-36.

Zaim, O., Färe, R. and Grosskopf, S. (2001) An economic approach to achievement and improvement indexes, Social Indicators Research, 56, 91-118. 


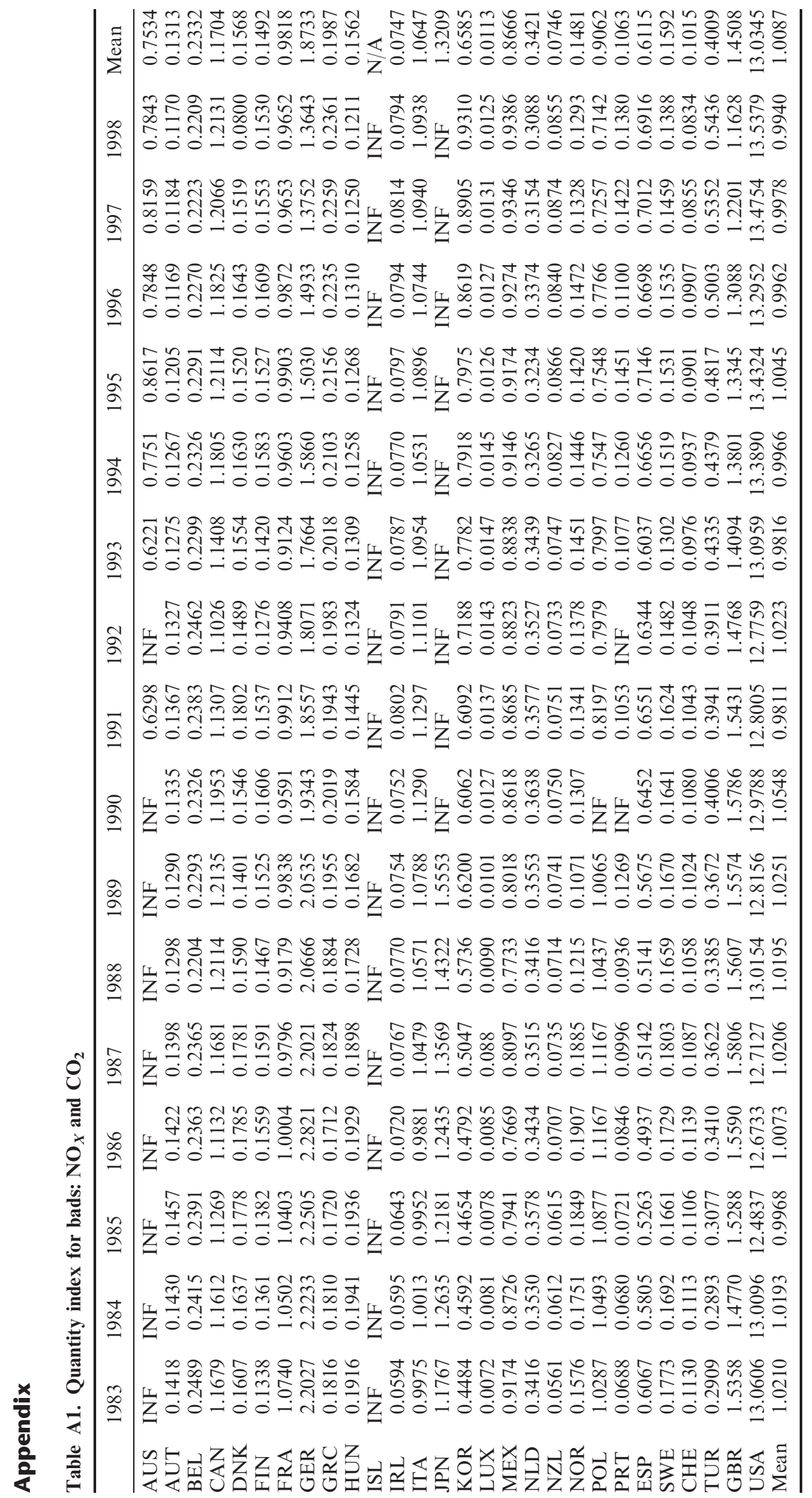




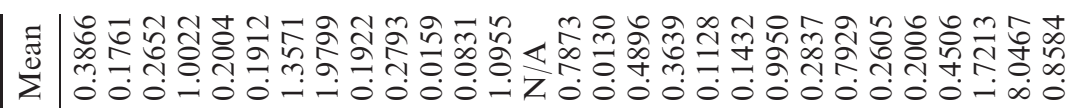

유면

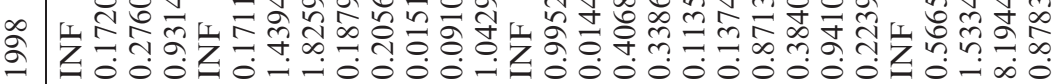

긍ำ

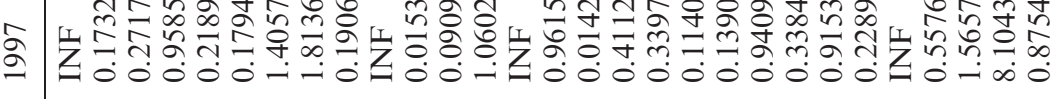

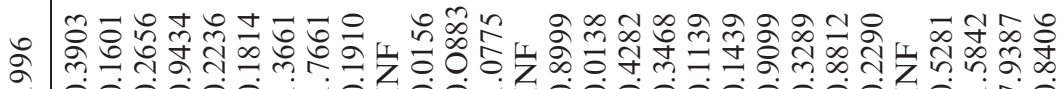

و

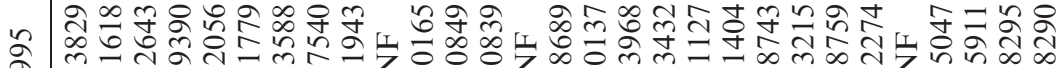

ま

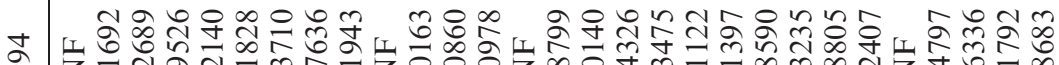

a Z

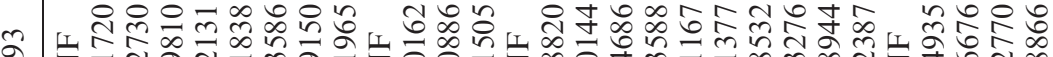

会

N

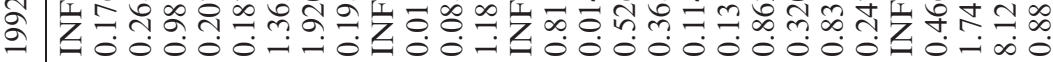

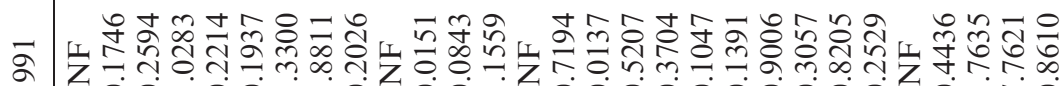

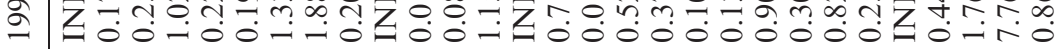

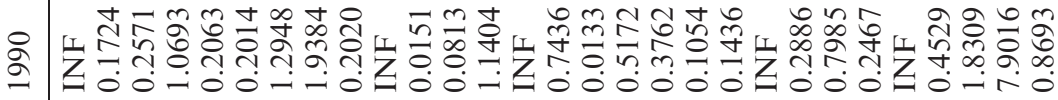

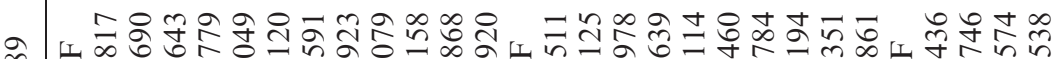

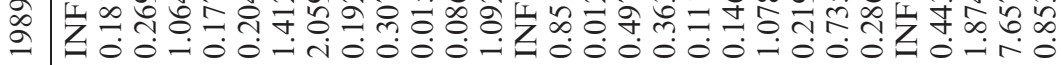

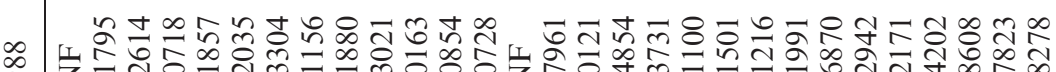

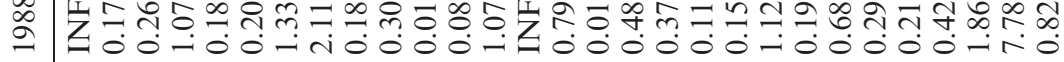

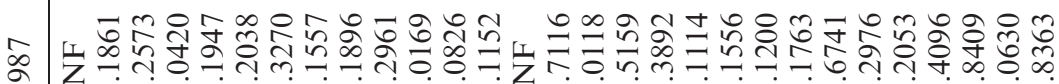

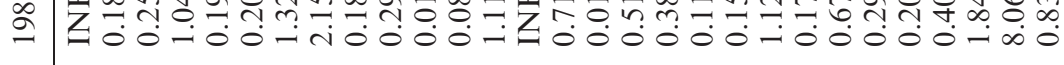

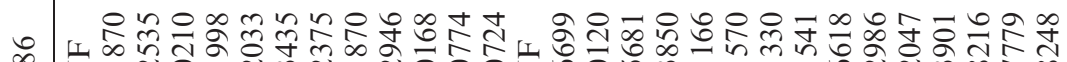

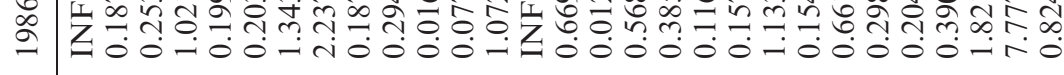

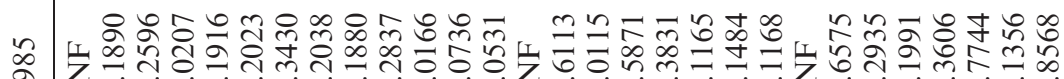

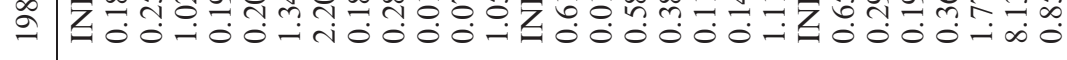

म

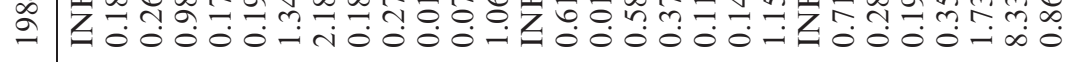

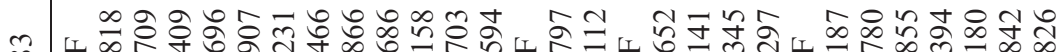

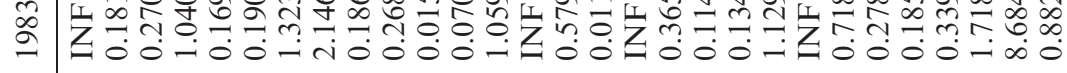

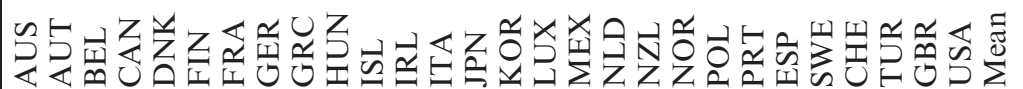




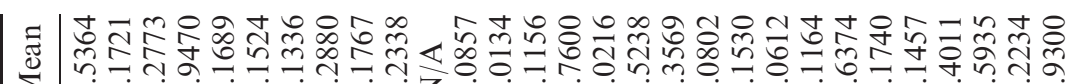

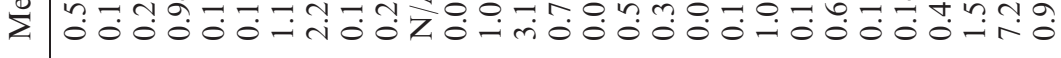

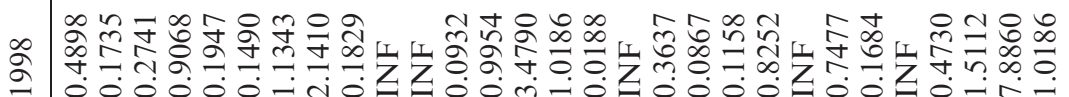

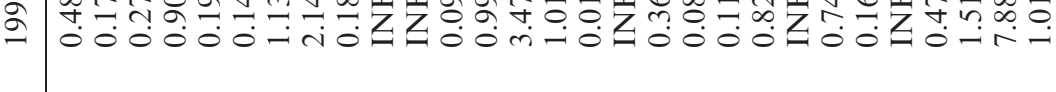

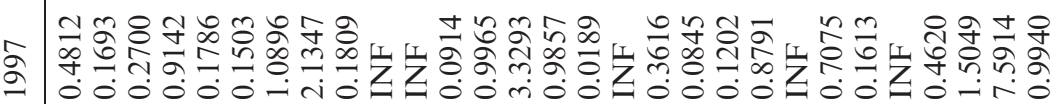

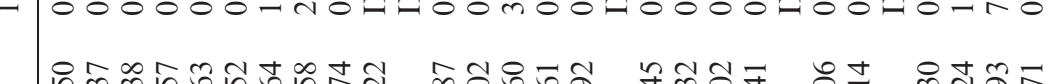

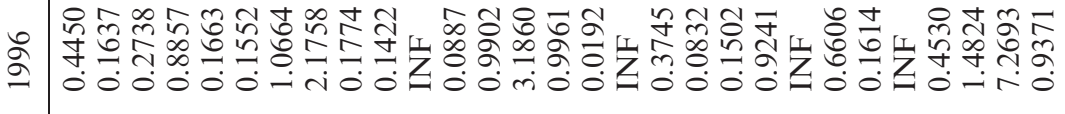

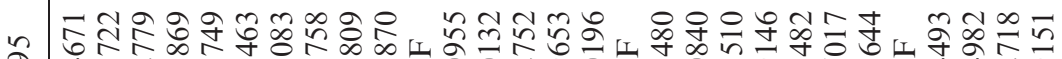

方

๙

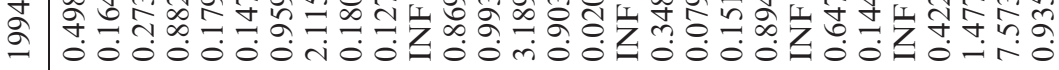

๙

a

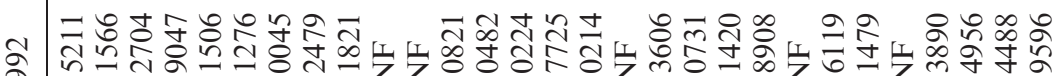

Ә

ত

ब

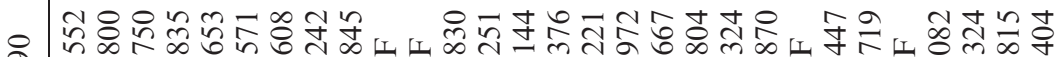

至

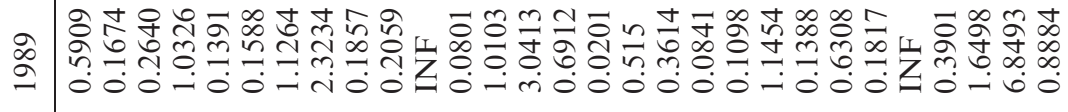

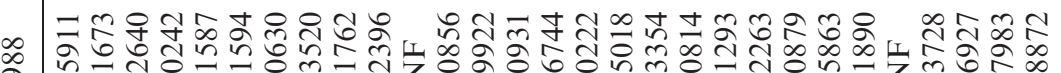

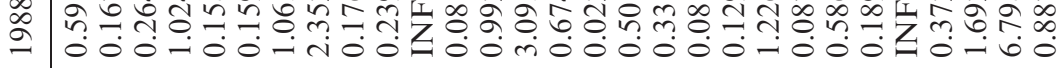

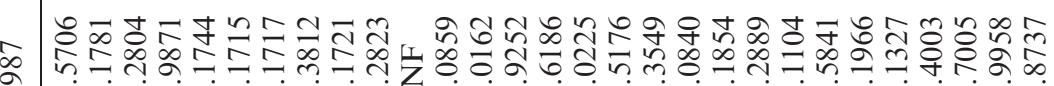

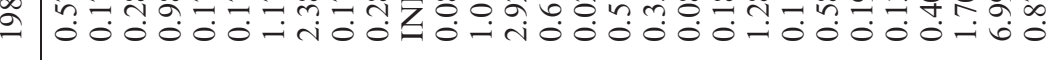

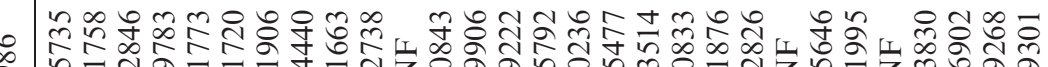

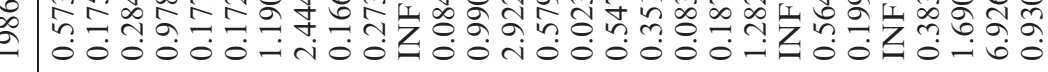

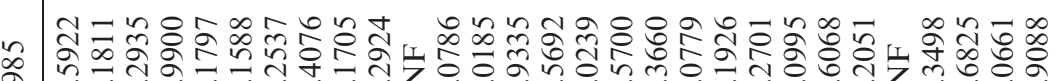

ڤ

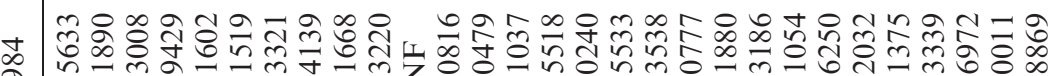

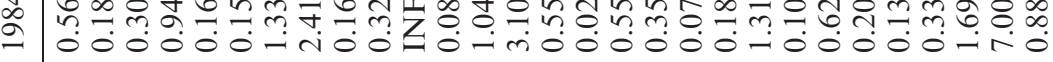

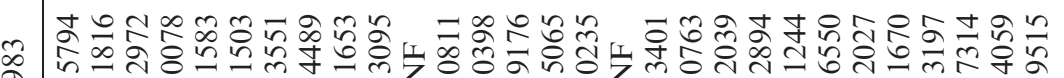

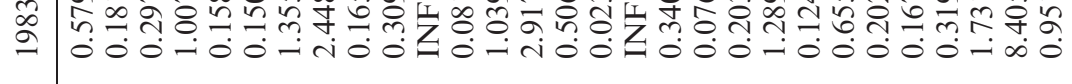

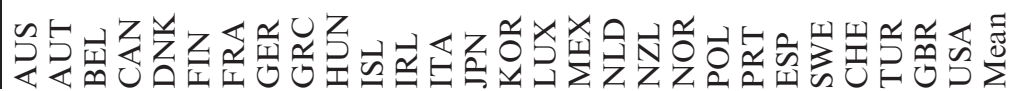

